\title{
Administration policy and techniques with effective leadership skills for managing change
}

\author{
*Michael Ndisika ${ }^{1}$ Lawrence O. Odeh ${ }^{2}$ \\ 1. Department of Sociology and Anthropology, Faculty of Social Sciences, University of Benin, Benin \\ City, P.M.B. 1154, Edo State, Nigeria \\ 2. Department of Political Science and Public Administration, Faculty of Social Sciences, Benson Idahosa \\ University, P.M.B. 1100, Benin City, Edo State, Nigeria \\ *Email of the corresponding author: ndismike2000@gmail.com
}

Abstract

The paper examined administrative tools and techniques with effective leadership skills for managing change in organizations, both public and private. This objective is of utmost necessity due to the fact that in this contemporary fluid, and dynamic character of business environments, the only constant that can be relied upon by professionals is change. The research paper depended on secondary sources of data collection. As result of an in-depth investigation of various scientific and professional reports on the issue, several administrative tools and techniques, as well as effective leadership skills for managing organizational change were identified. These are: careful planning, transparency and truthfulness to subordinates with respect to change process, communication with subordinates and team members about change initiatives, provision of training, creating a road map, don't expect to implement change overnight, invite participation, monitor and measure effects of change, apply explicit and implicit coercion in extreme cases, and so on.

Keywords: Management, administration, leadership, organization, strategy, change.

DOI: $10.7176 / \mathrm{DCS} / 11-8-05$

Publication date:November $30^{\text {th }} 2021$

\section{Introduction}

Harvard Business School Professor David Garvin observed that: "despite realizing that change is necessary, employees are often afraid of big changes in the organization, preferring the dissatisfaction of the status quo to the risks of a new reality" (Stobierski, (2020). In this contemporary fluid, and dynamic character of business environments, the only constant that can be relied upon by professionals is change. Organizations must be very flexible and quickin making decisions, and those that excel in these processes will experience a tremendous change in short duration (Krakoff, 2021). Companies must embrace change in order to assume a strategic position in the face of emerging technological and economic innovations and developments. A research and advisory company, Gartner, stated that the average business has embarked on five major organizational changes in the past three years. In the next three years, 75 percent of those companies desire to achieve additional change initiatives (Stobierski, 2020).

Organizational change is pursued to the fact that it will enable a business to operate at a higher level - becoming more efficient, productive, innovative, and profitable. Incorrect management of changecan be counter-productive to an organization, causing it a colossal loss, such as loss of productivity, and poor performance from employees. Gartner observed that only 34 percent of all organizational change initiatives are viewed as a "clear success", while 50 percent are considered "clear failures". The rest 16 percent produced "mixed results" (Stobierski, 2020). Change and resistance to change are two sides of the same coin. In most cases, any major change initiated in the work place receives a corresponding resistance from employees. Several factors have been attributed to that phenomenon: these are poor communication, mistrust, fear of failure, unrealistic timelines and so on. In the light of the above, effective change management can allay the fear and perceived discomfort due to the change envisaged by employees. A successful change management strategy go a long way to resolving the crises of resistance to change and become proactive in legitimizing organizational change by using change leaders, training tools, and engagement with employees (Sureh, 2021). In order to achieve the objective of this paper, it was divided in to various sections for proper and critical analyses of the issue under discussion. Some of the sections are: the 
theoretical definition of core terms used in the paper, theoretical frame work that is centred on Kurt Lewin's theory, literature review section, and so on.

\section{Definition of terms}

Meaning of Administration: "Administration", according to E.N. Gladden refers to "a long and slightly pompous word", but it has a humble meaning. The English word "administer" is derived from the Latin word "ad" and "ministrare" which means "to serve", "to care for" or "to look after people". It is a management process that takes place in all forms of organizations from the household to most complex system of the government. J.S. Hodgson describes administration as "a kind of activity found in both public and business affairs". Administration simply means the act of getting things done (Fadia\&Fadia, 2009, p. 1). In a similar development, Felix A, Nigro sees administration as"the organization and use of men and materials to accomplish a purpose". Herbert A. Simon, also, views it as the activities of groups cooperating to accomplish common goals". According to john A. Vieg:"Administration is determined action taken in pursuit of conscious purpose. It is the systematic ordering of affairs and the calculated use of resources, aimed at making those things happen which we want to happen and simultaneously preventing developments that fail to square with our intentions. It is the marshaling of available labour and materials in order to gain that which is desired at the lowest cost in energy, time and money" (Fadia\&Fadia, 2009; Naidu, 1996).

In the words of L.D. White, "the art of administration is the direction, co-ordination and control of many persons to achieve some purpose or objective". Luther Gulick is of the view that "administration is a process involving human beings jointly engaged inworking towards common goals", D. Waldo corroborated this view by stating that it is "a type of co-operative human effort that has a high degree of rationality". Brooks Adam added that administration is "the capacity of coordinating many and often conflicting social energies in a single organism, so adroitly that they shall operate as a unity(Fadia\&Fadia, 2009; Naidu, 1996). From the above stated definition of administration, it is very obvious that the term refers to a deliberate and conscious art of using human, financial, physical or material, and information resources to achieve a common specified goal.

Meaning of Leadership: leadership is of utmost significance to the overall success of an organization, especially in the aspect of organizational goal achievement. It is in this context that Prof. C.P. Bhambhri stated that: "an efficient organization is not born. It has to be created. The leader of the organization creates it". Similarly, Dimock and Dimock observed that "leadership is not power, nor dominance, nor social superiority, nor anything suggestive of snobbery". They concluded that "Leadership is influence with people, not power over them". Leadership has also been viewed as "the process of influencing the activities of others towards goal achievement." According to F.A. Nigro and L.G. Nigro, "the essence of leadership is influencing the actions of others; the essential quality of leaders is that they are convinced something must be done" (Naidu, 1996, p.201).In the light of the above, effective leadership utilizes the psychological tool of persuasion to influence organizational members, not the coercive instrument of force. Although the coercive instrument cannot really be avoided completely. It may be applied lightly in some extreme cases, especially when it is for the public good or survival of the organization.

There are several approaches to leadership: (i) the great man approach (leaders are born); (ii) the trait approach (certain character determines leadership); (iii) behavioral approach (certain behavior determines leadership); (iv) the situational approach (leadership based on circumstances). There are three types of leadership style: (i) autocratic (ii) democratic (iii) laissez-faire or free reign. The qualities of leadership are stated as follows: (i) intelligence (ii) communication skills (iii) empathy (iv) energy (v) sound judgment (vi) belief in the possibility of success (vii) integrity (viii) flexibility (ix) technical and professional competence (x) social skills.

Distinction between Leadership and Management: Most scholars have been sensitive in separating the definition of leadership from management because they are not synonymous concept as some may assume. The concept management refers to that mental and physical process which leads to directing other people to perform specific formal functions towards the realization of the organizational goals. Management basically centres on planning, organizing and controlling the work of other people to achieve organizational goals. Leadership, on the other hand, "is a higher order of capability. It is exercised not by the performance of individualtasks of 
management, but rather by the manner in which all executive functions are performed. It is specifically, exercised through the interpersonal interactions, between a leader and his subordinates, with the purpose of increasing organizational effectiveness" (Naidu, 1996, p. 201).

Leaders differ from managers in several ways. "The leader is the strategist that creates the organization's vision and objectives; the mangers focus is in how the organization will achieve the formulated vision by the leader. " Leaders are facilitators who help to pave the way towards the achievement of organization's goals. Managers, on the other hand, are performance of individual managerial tasks (Naidu, 1996, p.201-202).

Change Management: Change management is a systematic approach to dealing with the transition or transformation of an organization's goals, processes or technologies. The occurrence of change is to facilitatethe implementation of change policies, to direct the change, and rendering assistance to people to adapt and respond positively to the change process. The change management process must take into cognizance how the adjustment and other unusual processes brought about by the change will affect organizational systems, and employees. Change processes must be preceded by proper planning and adequate testing (Pratt, 2019). Change management is a structured approach to move organizations from one level of operation to a more preferred level. Change management orientation emanates from the view that change bring about certain discomfort to the people at work. Organizational change manifests as: (i) strategic changes, (ii) technological changes, (iii) corporate structural changes, (iv) changing the behavioural patterns of employees, and so on (Okorie, 2010). Change management is essential for the sustainability of organizations (Merriden, 2000).

Concept of Strategic Change: Strategic change refers to an alteration on corporate strategies in terms of employees, technology, structure and culture. Strategic change exhibits the following characteristics: (i) reorientation of corporate level strategic change, (ii) revitalization (rejuvenation of unhealthy organizations). The success of strategic change is attained when: (i) the organization has been taken from its present level to anticipated future level, (ii) the future state of the organization corresponds with what was expected, (iii) moving from the current state to the new desired level is cost efficient to the workers and organization. Strategic change is all about the transformation of the organization, moving to adesired future level as encapsulated in the strategic vision and mission (Davies, 1999, cited in Okorie, 2010).

What is Change Management Tool?: Change management tools refer to whatever is used to address crises situations brought about bythe unusual approach adopted in conducting the affairs of organizations, staff matters or organizational software. Change management tools could be applied in feedback mechanism, plans implementation, training programmes, restructuring and so on (What is Change Management Tool? (2021)).

Change Agent: Change agent refers to someone who is in charge of planning and managing the change initiatives. The change agent may come from outside the organization, such as external consultant/investor (entrepreneur) or he or she may be someone from within the organization (intrapreneur) (Okorie, 2010).

What is Organizational Change?:Organizational change refers to a situation where an organization alters certain vitals aspects of its operations. This change may occur in the organization's culture, technologies, structure, or very vital initiatives and goals (Stobiesrski, 2020).

Change Process: All change processes have point A as their starting point andpoint B, which is their endpoint. Everything that takes place between those two points is referred to as the change process. It is summarized into: preparation, implementation and follow-through (Stobiesrski, 2020).

\section{Theoretical framework}

This paper is anchored on the Kurt Lewin field force theory, which is centred on the maintenance of equilibrium by driving forces and opposing restraining forces. In initiating change, there is a sense of determination to increase the driving forces (change initiatives), which correspondingly increases resistances (opposition by workforce) by strengthening the restraining forces. The tendency is to either reduce or eliminate the restraining forces in order to 
move to new level of equilibrium. "In organizations, changes in policies experience less resistance when those social segments of the organization that are affected are made to participate in the change initiatives (Okorie, 2010). The relevance of this theory to this paper is based on the fact that the administrators are those who drive planned organizational change, while the remaining workforce are those who react and resist the change. So, it is now the responsibility of the administrators and other policy makers to try to counter those resistances due to change by using administrative tools and techniques, backed by effective leadership skills which this paper is design to achieve.

\section{Literature review}

\section{The Dynamics of Organizational Change}

Organizations are going through real unpremeditated pressure from their external environment which has made tremendous impacts on every segments of the organization (Hitt, 2000). Those external pressure needs to be mitigated by initiating organizational change, and at the same time managing the change in order to achieve optimum performance in the organization. Change management involves careful planning and thoughtful implementation/consultation with, those affected by the changes. The basic question associated with organizational change initiative and implementations are: what are the prospects of the change? Why was the change initiated and how will the change be attained? Who are those that are affected by this change, and how do they react? And what dimension of the change would need outside help? These questions are applicable to both individual and organizational change management. The genuine answer to the above questions corresponds to effective change management. The processes involved in the management of organizational are as follows: (i) change management techniques, (ii) engagement of senior managers as change leaders, (iii) awareness and advocacy building of the necessity for change, (iv) skills and knowledge development for the purpose of supporting the change, (v) assisting employees overcome the changing phase, and (vi) sustainability of change practices (Greenfield, 2008;Lorenzen, 2009; Okorie, 2010).

\section{Concept of Planned/Unplanned Organizational Change}

Change has been categorized into two types: (i) unplanned change (spontaneous, haphazard and random), these are very often destructive and as result needs urgent attention to mitigate its adverse consequences or maximize its utility, if any. Several organizational changes caused by the corona virus pandemic are a case study of unplanned change. (ii)Planned change (induced by change agents) is a deliberate effort to fill a gap in organization's performance. It is a problem oriented approach; it deals with challenges that may have emanated from within the organization or outside of it. Planned organizational change approach have two basic targets: (i) reacting to changes in the organizational environment (ii) and changing the behavioural patterns of the organizational workforce. The process of planned organizational changed is systematic and methodical, transiting from one phase to another (Beer e al, 1990). Planned organizational change is an organizational arrangement geared towards the perfection of changes in preparation for future challenges. Proactive organizations anticipate changes that are futuristic and respond to current changes through planning and creating adequate strategies (Okorie, 2010).

\section{Determinants of Change}

The following are the determinants of change: (i) change in corporate/individual objectives, (ii) purchase of new equipment/technology, (iii) scarcity of labour, (iv) implementation of a sophisticated information processing system, (v) government regulations, (vi) economic dynamics (economic depression and melt down, fluctuating fiscal and monetary policies, trade wars between countries leading scarcity of some goods and services), (vii) increased pressure from consumer - advocate groups, (viii)mergers or acquisition (ix) rapid changes in price or availability of raw materials, (x) actions of competitors, (xi) decline in workforce morale, (xii) increase in labour turnover, (xiii) sudden internal or external hostility and (xvi) decline in profit, and so on (SchermahonJr, 1984; Pascal et al, 1997; Hitt, 2006, cited in Okorie, 2010). 


\section{Guidelines for Successful Change Management}

Several obstacles to successful change have been identified. These are: (i) absence of proactive leadership, (ii) initiative burnout (short of inventive ideas), (iii)stifling cultures, (iv) lack of urgency and (v) poor implementation. These abnormalities can be addressed through adoption of proactive successful change management strategies. The guidelines for successful change include: (i) achievement of sustainable change is based on the availability of corporate leadership commitment, (ii) appreciation of corporate/organizational culture, (iii) change agents/managers at all levels should possess the requisite temperament and effective leadership skills, (iv) development of the appropriate change friendly work environment and learning organization, (v) commitment to change increases faster if change resistors participate in the planning and implementation, (vi) the reward system should be such which encourage innovation and recognize breakthrough in the achievement of change, (vii) change has both failure and success dimensions/lessons, (viii) hard evidence/ data drive change achievement (the display of rate of spread of covid 19 in both local and foreign press media helped in compliance to changes in organizations in an attempt to overcome the pandemic), (ix) change of behavior (by altering processes, structure and systems) is less difficult than change in attitudes/ corporate culture, $(\mathrm{x})$ change enthusiasts/ supporters should be made change agents, (xi) resistance to change is inevitable, (xii) protection of the interests of those affected by change (Petigrew and Whipp, 1991, cited in Okorie, 2010).

Eight steps to successful change are stated below: (i) increase urgency, (ii) build the guiding team (raise up the right people with the right emotional commitment/right mix of skills at all levels), (iii) get the corporate vision right (develop vision/strategy that are feasible, (iv) communicate/advocate for workforce, (v) empower actions (remove obstacles and encourage constructive feedback), (vi) create short-term wins (set aims that are achievable and embark on activities prioritization), (vii) don't give up (be determined and persistent in the changed process), (viii) make change stick (re-inforce the benefits of a successful change through recruitment/promotion of new change leaders, get the change embedded into organization's culture) (Petigrew and Whipp, 1991, cited in Okorie, 2010).

\section{Change Management Models}

\section{(i) Lewin (1951) Unfreeze-Change-Refreeze Model of Organizational Change.}

This model consists of three phases: (i) unfreeze (process by which the organization members have come to the realization of the need for a change. It serves as motivation to dissatisfied workforce to overcome all that have been keeping them from embracing change) (ii) Change, (moving to new level of change due to the introduction of new technology, change in the corporate structure, systems of culture) and (iii) Refreezing, (institutionalizing new behavior) training/development, apportioning reward to those who exhibit the expected new behavior. This stage is of paramount importance because not until the change is made permanent, those who have already imbibed the new culture may relapse to the status quo. Lewin's Model of organizational change has been adapted by scholars, such as Hughes (1991), Tannenbaun and Hanna (1958) and Judson (1991) cited in Okorie (2010).

(ii) Kubler - Ross Model: This model gave a description of person's emotional state as having the tendency to experience pain due to a situation of a considerable loss. When the theory is applied to the workplace environment, it shows that workers also experience emotional breakdown when they are faced with changes in the organization (Okorie, 2010).

(iii) Gleicher's Formula (Model) for Change:This is of the view that the organizational dissatisfaction, vision for the future and the likelihood of immediate action must be made stronger than the resistance within the organization so as to allow meaningful changes to occur (Okorie, 2010).

(iv) People Centred Implementation (PCI)Model:This model is centered on the six critical success factors that need to be managed in order to embark on change initiatives in organization. These factors are: (i) shared change purpose (ii) effective change leadership, (iii) powerful engagement processes, (iv) committed local sponsors, (v) strong personal connection, (vi) sustained personal performance (Okorie, 2010). 
(v) ADKAR Model:This model emphasized five factors responsible for individual change. ADKAR is the acronym for the five factors. These are: (i) Awareness- (of the necessity of the change), (ii)Desire- (be ready to make any contribution to the change process, (iii) Knowledge - (about the entire change process) (iv) Ability - (to carry out the change process), (v) Reinforcement (institutionalization of the change (Hitt, 2006).

(vi) Beckard's Model(1969): This model is based on necessary requirement of any change. These are: (i) setting goals, (ii) diagnosing the current situation in line with those goals, (iii) defining present realities on ground and examining the commitment required to meet future state of the organization, (iv) developing strategies and plans to manage this change, (v) analyzing the factors capable of hindering change initiatives (Okorie, 2010).

(vii) Thurley Model (1979):It postulates five strategies to manage change: (i) directive - this is imposition of change in crises situation without due consultation with the people, (ii) bargaining this is where power is shared between employers and employees, and any form of change must be planned by a general consensus of all organization members, (iii) hearts and minds - this is aimed at changing workforce attitudes, values and beliefs, (iv) analytical - this deals with the use of models of change and (v) action-based - this deals essentially with the type of managers behavior to effect change (Okorie, 2010).

(viii) Bandura Model (1986): This model describes the patterns of change in people, such as: (i) people's behavior is based on conscious choices; (ii) the environment is a source of information needed in choice making. The choices people make are based on the following: (a) issues or things that are important or that are of utmost concern, (b) the perception of people regarding their abilities to behave in certain ways, (c) the consequences of behavior of the people (Okorie, 2010). The following are the implications of Bandura's model in the management of change: (i) the degree of association between certain behavior and certain outcome, have an impacts on the rate of engagement in that behavior, (ii) a favourable outcome engenders a corresponding behavior that gave rise to that outcome; (iii) indulgence in a new behavior is basedon confidence. Therefore, to change the behavior of individuals require a change in the work environment; achievement of new patterns of behavior that can cope with changes in the organization requires training and retraining (Okorie, 2010).

\section{Resistance to Change}

Organizations that have embarked on change will eventually face workforce resistance. The most destructive of these resistance result from workers refusal to support the process of change when it is necessary for them to do so. The change process is of two dimensions: (i) leaders need signals of an impending change, make plans for actions in advance, make provision for resources and give support to implementation; (ii) followers (followers are needed for any meaningful change to occur, not all followers will support change, many will resist it, so identify the change vanguard and work with them). Resistance to change emanates from two different sources. These are: (i) the individual and (ii) the organization. To successfully interact with organizational and individual sources of work place resistance, change agents should first understand where the resistance is coming from. Paradoxically, resistance to change has been identified to have positive effects on change by creating avenues for positive re-evaluation/examining several issues that are of importance (Schneider et al, 1996; Okorie, 2010).

Sources of resistance have been identified below: (a) organizational sources of resistance are as follows: (i) organizational structure; (ii) narrow scope of change; (iii) group inertia (desire to remain in the status quo); (iv) threatened power and influence (power and influence redistribution and reduction); (v) resistance to the allocation of resources; (vi) organization culture (which are not easy to change due to its long time formation); (vii)maintain stability (viii) investment of resources; (ix) past contracts with third parties tend to cause changes in behavior (O' Halloran, 2000). (b) the resistance to change caused by individuals are as follows: (i) habit (individuals tend to resist any attempt made to change their behavior); selective perception of individuals; (iii) economic factors. For example, (i) the individual may experience income reduction due to change; (ii) to survive change may be based on new learning, the cost of which may be borne by the individuals thereby 
leading to a reduction in income; (iv) security (change may trigger certain psychological imbalance due to a change from the status quo; (v) social factors (for example, someone may be displaced from a prestigious office position due to changes in the organizational structures); (vi) lack of understanding (of the change process by individuals) (Paschal et al, 1997).

Reduction of negative resistances to change is key to resolving resistance to change. Reaction to perceived threat that accompanies planned and unplanned change towards realization of change objectives and goals causes resistance. Six approaches for dealing with resistance are highlighted below. (i) education and communication; (ii) participation and involvement of workers in the change process; (iii) facilitation and support (given palliatives where necessary due to pains that may accompany certain change); negotiation and agreement ( with organization members prior to change initiatives to win their support); (iv) negotiation and agreement (with organization members prior to the introduction of change to win their respect); manipulation and cooperation (persuade resistors to key into the change agenda); (vi) explicit and implicit coercion (adopt the application of force, utilitarian (money) and normative or symbolic (moral persuasion) approaches force acceptance depending on the prevailing situation of change (Johnson and Scholes, 1999).

\section{ADMINISTRATION TOOLS AND TECHNIQUES WITH EFFECTIVE LEADERSHIP SKILLS FOR MANAGING CHANGE}

Despite the fact that some change can bring about positive development, most people have phobia for it and are therefore not comfortable with it. Most workers perceive changes in organizational processes as only a negative occurrence, such as the termination of job appointment due to either right sizing or downsizing of the organization, phobia for a new manager, team restructuring leading to loss of close allies, organizationwide layoffs, due to introduction of new technology, drastic reduction in salaries and allowances as a result of undue market competitiveness of economic depression, such as the financial meltdown of 1980s and 2015, and so on. It is your responsibility as a leader and manager to redirect your team's conception of change and position yourself to champion an effective organizational change. Note that the management of organizational change is an essential dimension of leadership (Krakoff, 2021). The next section of this paper is a discussion on the various administrative tools and techniques for managing change in organizations.

1. Plan Carefully:Prior to the introduction of your proposed change to your team, ensure that you have already devised a clear and unambiguous plan that addresses the when, how, and why of the proposed change. Identify the various tasks that would be of necessity to connect you to your place of desire, state categorically new or changing responsibilities for any affected persons, come-up with time frame, for the change process and devise responses to tackle issues that may arise from the change.

2. Be as Transparent as Possible:For major change, it is inevitable toexhibit transparency with your employees, despite the fact that you decided to keep some details from them, being sincere with the aspects you decided to share will in no small measure contribute to the comfort of your staff.

3. Tell the Truth: the safest means of attaining the goals of organizational change is to be honest with your staff to the best of your ability. Sugar-coating, over-exaggerating of plans and giving the promises of outcomes that are unrealistic will lead to your staff becoming suspicious and distrustful of your intentions. While it is expedient that managers' exhibit traits of optimism to your team, ensure that you acknowledge potential challenges and pitfalls.

4. Communication: Ensure that there are no communication barriers between you and your employees. Set aside time to explain the reason for the change, and its practical implications. Be available to entertain any question regarding the initiated change or proposed changes, hold team meetings frequently to get feedback from the change process.

5. Create a Road Map: Assist your workers to know the current state of the organization, where it is coming from, and where it is heading to. How was the change introduced into the organizational setting, and what are its impacts to its future. Putting those things in the right perspectives will indicate the direction of the change process. 
6. Provide Training: When the change introduced into the organization is such that entails shift in paradigm or a revolutionary drift in technologies or processes, ensure that there is provision for the required training for organizational staff to assist them cope in the post change era.

7. Invite Participation: One foremost strategy of managing change in the work place is to allow employees to participate in decision making, or give feedback. Employees will show much gratitude in being afforded the privilege to make decision input, and it invariably opens doors for means to acquire diverse views and understand impacts that may have never been considered.

8. Don't Expect to Implement Change Overnight: Changes that occur within longer periods of time are usually more meaningful and impactful than that which is hastily implemented. This will afford your employees enough time to adapt to the change.

9. Prepare for Roadblocks: No matter your state of readiness for a change, everything will not always be in line with your plan. You must expect certain unintended consequences of your change process they you will later prepare you to rectify them properly. That does not mean you are in the wrong track, but it means you have only discovered obstacles to your change. Don't you ever give up! Try again.

10. Apply both Explicit and Implicit Coercion When Necessary: Apply force, utilitarian or monetary and normative or symbolic (appeal to emotion) approaches to force acceptance of change on organization's members, especially where the change is of paramount importance to humanity and the existence of the business. In this case, the coercive approach will only be adopted after the normative and the utilitarian approaches have failed (Johnson and Scholes, 1999).

11. Demonstrate Strong Leadership: Inspire your employees; exhibit strategic thinking; demonstrate open-mindedness and flexibility; create an avenue for your team to trust you. A strong leader assists his team "weather the storms of change with confidence and clear sightedness, no matter how challenging it might be."

12. Monitor and Measure: as soon as the change is embarked upon, there should be corresponding oversight of the implementation process to ensure compliance of the change with the intent of the change (Johnson and Scholes, 1999; Krakoff, 2020;Stobierski, 2020).

\section{Conclusion}

Administration refers to a deliberate and conscious art of using human, financial, physical or material, and information resources to achieve a common specified goal. CDimock and Dimock view leadership as "influence with people and not power over them. Leadership and management are not synonymous terms, while management basically centres on planning, organizing and controlling the work of other people to achieve organizational goals; leadership on the other hand, is particularly exercised through the interpersonal interactions, between a leader and his subordinates, with the purpose of increasing organizational effectiveness.

The paper examined several models of change, such as Lewin (1951) unfreeze-change-refreeze model of organizational change, Kubler-Ross model, Gleicher's Formula (model) for change, people centered implementation (PCI)model, ADKAR model and so on. Also, several administrative tools and techniques for managing change were identified in the paper. These are: plan carefully, be as transparent as possible, tell the truth, communication barrier between management and employees should be removed, create a road map, provide training, invite participation, don't expect to implement change overnight, and so on.

\section{References}

Beer, M., Eisenstat, R. \& Spector, B. (1990). Why change programmes do not produce change. Harvard Business Review, 68 (7).

Fadia, B.L. and FadiaKuldeep (2009).Public administration. Agra: SahityaBhawan Publications.

Greenfield, A. (2008). The 5 forces of change-A blue print for leading a successful change. England:Management Books.

Hitt, M. (2000). The new frontier: Transformation of management for the new millennium. Organization Dynamics, 28 (3).

Hitt, J. (2006). ADKAR: A model for change in business, government. The Community, Learning Centre Publications. Loveland. 
Johnson, G. and Scholes, L. (1999). Exploring Corporate Strategy. New York: Prentice Hall.

Krakoff, Sonya (2021). The 10 best organizational change management strategies. Champlain College Online. Retrieved from online.champlain.edu, on the $12^{\text {th }}$ July, 2021.

Lorezen, M. (2009). 'Change management'. In Fritz Jack, Mistakes in library management: grievous error and how to avoid them. N.p: Scarecrow press.

Merriden T. (2000). A turnaround in progress. Management Review 24 (8).

Naidu, S.P. (1996). Public Administration: Concepts and theories. New Delhi: New Age International (P)Limited Publishers.

O’ Halloran, B. (2000). Will clicks replace clerks. Business and Finance, 24 (8).

Okorie, Nwabueze Ernest (2010). Managing change in organizations: The critical issues and dimensions.African Journal of Contemporary Issues, 10 (3).

Paschal, R., Millemam, M. and Gioja, L. (1997). Changing the way we change. Harvard Business Review, 75 (6).

Pratt, Mary K. (2019, July 29). Change management. Citrix. Retrieved from searchcio.tech target.com, on $11^{\text {th }}$ July, 2021.

Schneider, B., Brief, A. and Guzzo, R. (1996).Creating a climate and cuture for sustainable organizational change. Organization Dynamics, 24 (4).

Stobierski, Tim (2020, January 23). 5 tips for managing change in the workplace. Harvard Business School Online. Retrieved from online.hbs.edu, on $12^{\text {th }}$ July, 2021.

Sureh, Gokul (2021, July 4). 15 best change management tools for managing change. Whatfix. Retrieved from whaffix.com $>$ blog $>$ change.

What is Change Management Tool? (2021). In digitalprojectmanager.com, retrieved on 12 $2^{\text {th }}$ July, 2021. 